CZASOPISMO INŻYNIERII LA¿OWEJ, ŚRODOWISKA I ARCHITEKTURY JOURNAL OF CIVIL ENGINEERING, ENVIRONMENT AND ARCHITECTURE JCEEA, t. XXXIII, z. 63 (1/II/16), styczeń-marzec 2016, s. 193-200

\author{
Anna CHOMICZ-KOWALSKA ${ }^{1}$ \\ Krzysztof MACIEJEWSKI ${ }^{2}$ \\ Piotr RAMIĄCZEK
}

\title{
WPŁYW RODZAJU ASFALTU NA WŁAŚCIWOŚCI LEPKOSPRĘŻYSTE MIESZANEK MINERALNO- CEMENTOWYCH Z ASFALTEM SPIENIONYM
}

\begin{abstract}
Artykuł prezentuje wyniki badań właściwości lepko-sprężystych mieszanek mineralnocementowych $\mathrm{z}$ asfaltem spienionym (MCAS) wytwarzanych laboratoryjnie $\mathrm{w}$ technologii recyklingu głębokiego na zimno, z uwzględnieniem klasy penetracji użytego lepiszcza $(35 / 50,50 / 70,70 / 100)$. Mieszanki recyklowane zawierały w swoim składzie $50 \%$ destruktu asfaltowego, 30\% destruktu kamiennego oraz 20\% nowego kruszywa doziarniającego. Spoiwem hydraulicznym był cement portlandzki klasy 32,5 który dozowano w ilości 2,0\%, a nowe lepiszcze w formie piany asfaltowej dodawano w ilości $2,5 \%$. Próbki walcowe zagęszczane w prasie żyratorowej do zadanej gęstości objętościowej, poddawano oddziaływaniu obciążenia cyklicznego w schemacie ściskania, zgodnie z normą AASHTO TP $62-07$ (2009) w każdej z kombinacji temperatur $\left(-10^{\circ} \mathrm{C}\right.$, $\left.4^{\circ} \mathrm{C}, 21^{\circ} \mathrm{C}, 37,4^{\circ} \mathrm{C}\right)$ oraz częstotliwości $(25 \mathrm{~Hz}, 10 \mathrm{~Hz}, 5 \mathrm{~Hz}, 1 \mathrm{~Hz}, 0,5 \mathrm{~Hz}, 0,1 \mathrm{~Hz})$. Dla każdej z trzech mieszanek różniących się rodzajem użytego lepiszcza uzyskano wartości zespolonego modułu sztywności oraz odpowiadających im kątów przesunięcia fazowego. Dzięki zastosowaniu zasady superpozycji temperaturowo-czasowej możliwe było przesunięcie w domenie częstotliwości danych eksperymentalnych uzyskanych w różnych temperaturach. Dopasowanie funkcji sigmoidalnych umożliwiło stworzenie krzywych wiodących zespolonego modułu sztywności i kątów przesunięcia fazowego będących funkcją częstotliwości obciążenia. Ujęcie szerokiego spektrum danych eksperymentalnych w postaci krzywych wiodących pozwoliło porównać ze sobą właściwości lepkosprężyste badanych mieszanek MCAS. W efekcie stwierdzono niewielkie różnice między mieszankami z nowym lepiszczem o penetracji 50/70 i 70/100, mieszczące się $\mathrm{w}$ granicy dokładności metody, natomiast dla mieszanki $\mathrm{z}$ asfaltem spienionym na bazie lepiszcza 35/50 zanotowano odmienny charakter.
\end{abstract}

Słowa kluczowe: asfalt spieniony, mieszanka mineralno-cementowa $\mathrm{z}$ asfaltem spienionym (MCAS), recykling głęboki na zimno, podbudowa, moduł zespolony

\footnotetext{
${ }^{1}$ Autor do korespondencji/corresponding author: Anna Chomicz-Kowalska, Politechnika Świętokrzyska, al. Tysiąclecia Państwa Polskiego 7, 25-314 Kielce, akowalska@tu.kielce.pl

2 Krzysztof Maciejewski, Politechnika Świętokrzyska, al. Tysiąclecia Państwa Polskiego 7 , 25-314 Kielce, kmaciejewski@tu.kielce.pl

${ }^{3}$ Piotr Ramiączek, Politechnika Świętokrzyska, al. Tysiąclecia Państwa Polskiego 7, 25-314 Kielce, piotrr@tu.kielce.pl
} 


\section{Wstęp}

Technologia recyklingu głębokiego na zimno stosowana jest w Polsce od niemal 20 lat pod postacią mieszanek mineralno-cementowo-emulsyjnych (MCE) i sukcesywnie zdobywa coraz większą popularność na terenie całego kraju. Od 2010 roku wdrażane są w budownictwie drogowym również recyklowane podbudowy $\mathrm{z}$ mieszanek mineralno-cementowych $\mathrm{z}$ asfaltem spienionym (MCAS), w szczególności w województwie świętokrzyskim, gdzie w technologii tej dotychczas przebudowano ponad $40 \mathrm{~km}$ dróg, w tym głównie wojewódzkich obciążonych ruchem KR4 $[2,3]$. Na przestrzeni lat technologia mieszanek MCAS potwierdziła swoją skuteczność jako szybki i efektywny sposób przebudowy zużytych warstw konstrukcji nawierzchni w nową pełnowartościową podbudowę. Jednakże do chwili obecnej nie badano w szerszym zakresie własności lepkosprężystych tego typu materiału. W Polsce, w początkowym etapie wdrażania mieszanek MCAS stosowano głównie specjalne lepiszcza asfaltowe przeznaczone do spieniania o penetracji z zakresu 70/100 [2], ale w późniejszym okresie, opierając się na pozytywnych wynikach badań laboratoryjnych stosowano już tylko ogólnodostępne tańsze asfalty drogowe klasy 50/70 [2,3]. Badania laboratoryjne wykazały, że w technologii mieszanek MCAS możliwe jest również stosowanie asfaltów klasy 35/50 [2, 3, 7]. Wykonywane na przestrzeni lat odcinki dróg z podbudową $\mathrm{z}$ asfaltem spienionym na bazie asfaltu 50/70 i 70/100 ujawniły niewielki wpływ rodzaju użytego lepiszcza na właściwości warstwy podbudowy, jednakże coraz szersze stosowanie tej technologii w naszych warunkach klimatycznych sprawia, że zagadnieniu temu należy poświęcić więcej uwagi.

\section{Materiały i metoda badawcza}

Ocenę właściwości lepkosprężystych mieszanek MCAS w aspekcie rodzaju lepiszcza użytego do technologii spieniania $\left(\mathrm{MCAS}_{35 / 50}, \mathrm{MCAS}_{50 / 70}, \mathrm{MCAS}_{70 / 100}\right)$, wykonano w oparciu o wyniki oznaczania zespolonego modułu sztywności, oznaczanego $\mathrm{w}$ schemacie bezpośredniego cyklicznego ściskania, zgodnie $\mathrm{z}$ normą AASHTO TP 62-07 (2009). Mieszanki wytwarzano w całości w laboratorium, symulując zastosowanie technologii recyklingu głębokiego na zimno, analogicznie jak w $[4,8]$. Oznaczenia wykonywano na rdzeniach o średnicy $100 \mathrm{~mm}$ i wysokości $150 \mathrm{~mm}$ wywierconych z próbek cylindrycznych o wymiarach $150 \mathrm{~mm}$ x $200 \mathrm{~mm}$ zagęszczanych w prasie żyratorowej. Zawartość wolnych przestrzeni w próbkach wynosiła $11 \%( \pm 1 \%)$. Dla każdej z mieszanek wykonano po 4 próbki, na których zamontowano po 3 czujniki LVDT. Mieszanki badano w temperaturze: $-10^{\circ} \mathrm{C}, 4^{\circ} \mathrm{C}$, $21^{\circ} \mathrm{C}$ i $37,4^{\circ} \mathrm{C}$ oraz przy częstotliwości $25 \mathrm{~Hz}, 10 \mathrm{~Hz}, 5 \mathrm{~Hz}, 1 \mathrm{~Hz}, 0,5 \mathrm{~Hz}, 0,1 \mathrm{~Hz}$.

W składzie badanych mieszanek MCAS o właściwościach podanych w $[4,8]$ stosowano 50\% destruktu asfaltowego, 30\% destruktu kamiennego oraz 20\% kruszywa doziarniającego. Jako środki wiążące stosowano cement klasy 32,5 w ilości $2 \%$ oraz asfalt spieniony w ilości $2,5 \%$. 


\section{Zespolony moduł sztywności i krzywe wiodące}

W pierwszej kolejności wyniki uzyskane $\mathrm{w}$ badaniach przedstawiono $\mathrm{w}$ formie wykresów Cole-Cole (rys. 1) i krzywych Blacka (rys. 2). Analiza charakterystyk asfaltów i mieszanek mineralno-asfaltowych (mma) w tych przestrzeniach pozwala wnioskować, czy badany materiał spełnia warunki ciała termoreologicznie prostego $[6,10]$, w przypadku którego można zastosować zasadę superpozycji temperaturowo-czasowej (time-temperature superposition principle, TTSP).

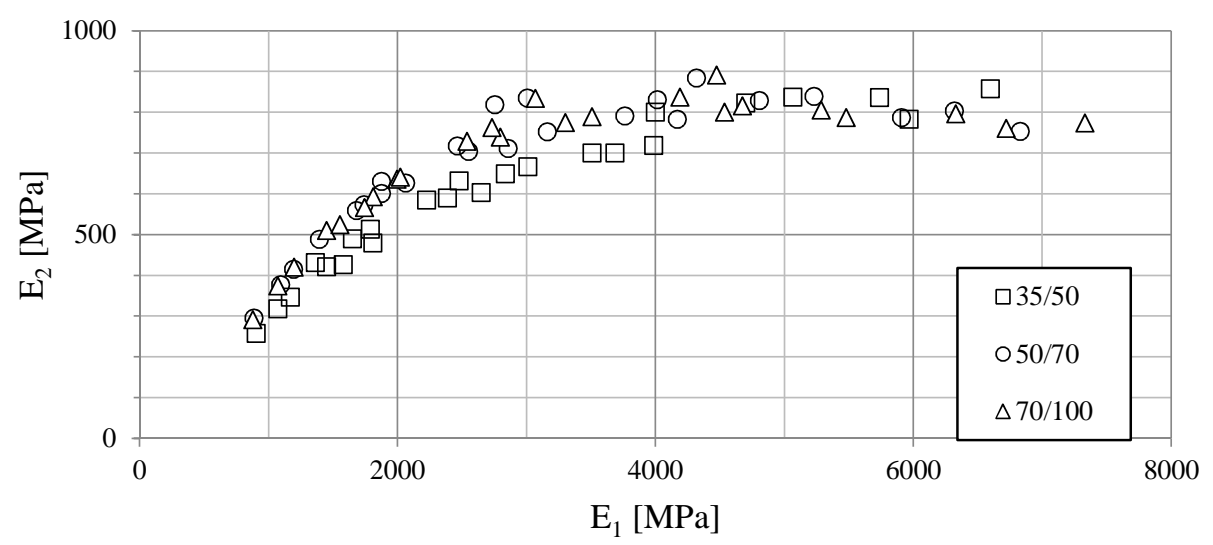

Rys. 1. Wykres Cole-Cole badanych mieszanek MCAS z asfaltem spienionym o penetracjach 35/50, 50/70 i 70/100

Fig. 1. Cole-Cole complex modulus diagram of cold recycled mixtures (CRM) with 35/50, 50/70 and 70/100 foamed bitumen

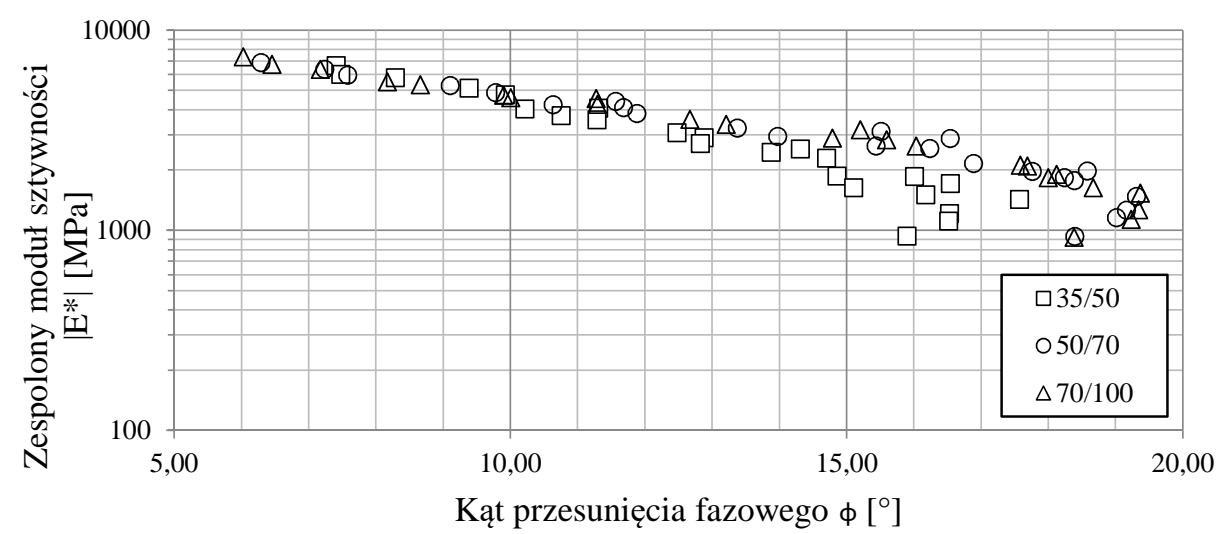

Rys. 2. Wykresy Blacka badanych mieszanek MCAS z asfaltem spienionym o penetracjach 35/50, 50/70 i 70/100

Fig. 2. Black diagram of tested CRM mixtures with with $35 / 50,50 / 70$ and 70/100 foamed bitumen 
Wykres Cole-Cole w opisywanym przypadku przedstawia zależności między częścią rzeczywistą zespolonego modułu sztywności $E_{l}$ a częścią urojoną $E_{2}$. Przy większych wartościach modułów $E_{l}$ (wysokie częstotliwości lub niskie temperatury) zaobserwować można poziomy przebieg uzyskanych krzywych. $\mathrm{W}$ badanym zakresie niskich temperatur i wysokich częstotliwości nie odnotowano charakterystycznego dla mma $\mathrm{w}$ technologii na gorąco zmniejszania się wartości modułu $E_{2}$. Obraz charakterystyk badanych recyklowanych mieszanek w przestrzeni Blacka silniej ujawnia różnice między mieszanką $\mathrm{MCAS}_{35 / 50}$ a pozostałymi dwoma. Krzywa dla tej mieszanki nie tylko przebiega wyraźnie niżej, ale również w zakresie kąta przesunięcia fazowego $14^{\circ}-17^{\circ}$ (zakres wysokich temperatur) wykazuje znamiona utraty ciągłości. Analiza charakterystyk badanych mieszanek na rysunkach 1 i 2 pozwala uznać (w zakresie niskich i średnich kątów przesunięcia fazowego) że krzywe te są ciągłe, ale dodatkowa ostrożność jest wymagana przy analizowaniu wyników mieszanki $\mathrm{MCAS}_{35 / 50}$.

Klasycznie uznaje się, że zasadę TTSP można stosować w zakresie niewielkich odkształceń, gdzie obserwowana jest liniowa lepkosprężystość lepiszczy i mma (odpowiednio do ok. $1 \%$ dla asfaltów i ok. $100 \mu \mathrm{m} / \mathrm{m}$ [1]). Szereg badaczy wykazało jednak słuszność tej zasady w obszarze nieliniowej odpowiedzi mma (nawet w obliczu takich zjawisk jak przyrost odkształceń trwałych czy rozwój pęknięć) [9, 11]. Obserwacje te oraz analiza rysunków 1 i 2 pozwala przewidywać, że zasada TTSP będzie obowiązywała dla badanych mieszanek MCAS. Tym samym, powinno być możliwe przesunięcie uzyskanych wyników $\mathrm{z}$ różnych temperatur w domenie częstotliwości i uzyskanie krzywych wiodących w temperaturze referencyjnej $20^{\circ} \mathrm{C}$.

Wielkość przesunięcia wyników eksperymentalnych ujmuje współczynnik przesunięcia temperaturowego $a_{T}$ definiowany zgodnie z równaniem (1). Jego wartość zależna jest od różnicy logarytmu częstotliwości zredukowanej $f_{\text {red }}$ i rzeczywistej $f$. Do obliczenia wartości współczynników $a_{T}$ zdecydowano się wykorzystać zależność Williamsa-Landela-Ferry'ego (WLF) zgodnie z równaniem (2), gdzie $C_{I}$ i $C_{I I}$ to stałe współczynniki dopasowania, $T$ to temperatura badania a $T_{r e f}$ to temperatura referencyjna dla której konstruowana jest krzywa wiodąca.

$$
\begin{gathered}
\log f_{\text {red }}-\log f=\log a_{T} \\
\log a_{T}=-\frac{C_{I}\left(T-T_{r e f}\right)}{C_{I I}+T-T_{\text {ref }}}
\end{gathered}
$$

Do modelowania krzywych wiodących wybrano funkcję sigmoidalną (3):

$$
\log \left|E^{*}\right|=\delta+\frac{\alpha}{1+\exp \left(\beta+\gamma \log f_{\text {red }}\right)}
$$


Jako że parametry $(\alpha, \beta, \gamma$ i $\delta)$ tej funkcji nie reprezentują rzeczywistych właściwości badanych mieszanek, konieczne było wykonanie jednoczesnego dopasowania wartości zarówno dwóch stałych $C_{I}$ i $C_{I I}$ funkcji WLF, jak również parametrów $\alpha, \beta, \gamma$ i $\delta$ (tabela 1). Do tego celu posłużono się metodą najmniejszych kwadratów, minimalizując sumę kwadratów różnic między przesuniętymi w domenie częstotliwości pomierzonymi wartościami zespolonego modułu sztywności a dopasowywaną krzywą wiodącą (rys. 3).

Tabela 1. Wartości stałych opisujących przebieg krzywych wiodących modułów zespolonych Table 1. Fitted parameters for constructing complex moduli master curves

\begin{tabular}{|c|c|c|c|c|c|c|}
\hline Mieszanka & $\boldsymbol{C}_{\boldsymbol{I - 2 0 0 ^ { \circ }} \mathbf{C}}$ & $\boldsymbol{C}_{\boldsymbol{I I - 2 0 ^ { \circ }} \mathbf{C}}$ & $\boldsymbol{\alpha}$ & $\boldsymbol{\beta}$ & $\boldsymbol{\gamma}$ & $\boldsymbol{\delta}$ \\
\hline$M C A S_{35 / 50}$ & 182,01 & 1314,98 & 19,7 & $-2,21$ & $-0,06$ & $-14,45$ \\
\hline$M C A S_{50 / 70}$ & 74,75 & 607,45 & 47,14 & $-3,76$ & -013 & $-42,77$ \\
\hline$M C A S_{70 / 100}$ & 216,87 & 1769,59 & 8,71 & $-1,85$ & $-0,12$ & $-4,18$ \\
\hline
\end{tabular}

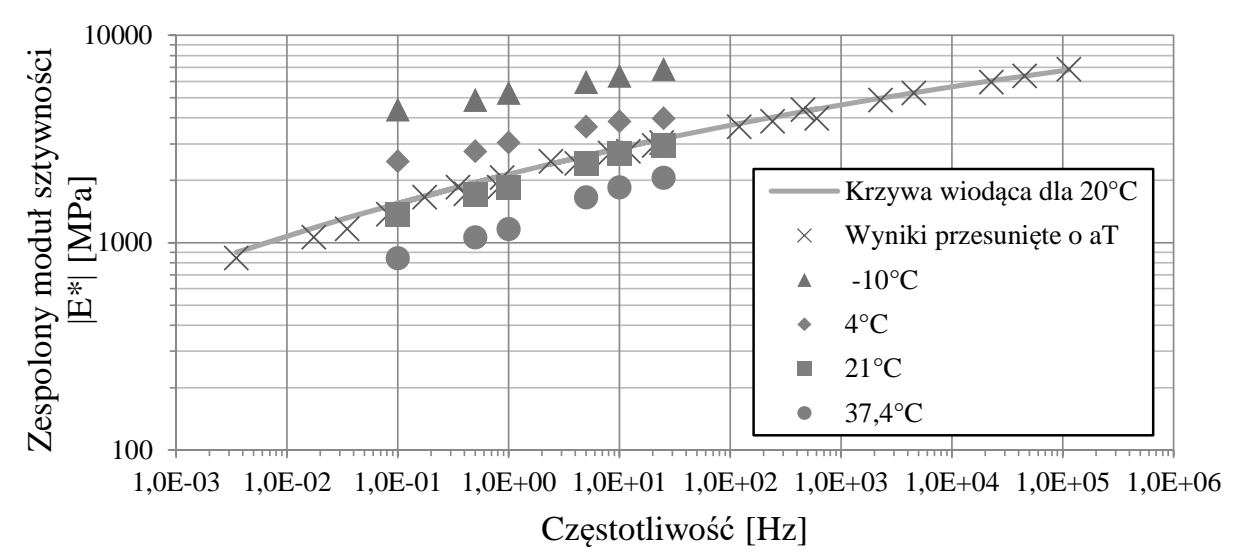

Rys. 3. Sposób budowy krzywej wiodącej dla modułu zespolonego na przykładzie mieszanki MCAS50/70

Fig. 3. Master curve of CRM mixes with 50/70 foamed bitumen

Na rysunku 4 przedstawiono krzywe wiodące zespolonych modułów sztywności w temperaturze referencyjnej $T_{r e f}=20^{\circ} \mathrm{C}$, odpowiadające trzem mieszankom MCAS zawierających $w$ swoim składzie nowe lepiszcze $w$ formie asfaltu spienionego wytworzonego z asfaltów różniących się klasą penetracji. Podobnie jak na wykresach Cole-Cole i krzywych Blacka, zauważyć można odmienne zachowanie mieszanki $\mathrm{MCAS}_{35 / 50}$, szczególnie w zakresie niskich częstotliwości (wysokich temperatur). Przebieg krzywych wiodących wskazuje na mniejszą wrażliwość temperaturową mieszanki z najtwardszym lepiszczem, wyrażoną wartością zespolonych modułów sztywności o ok. $200 \mathrm{MPa}$ większą w zakresie najniższych częstotliwości oraz niższą o ok. 1000 MPa w zakresie wysokich częstotliwości. 


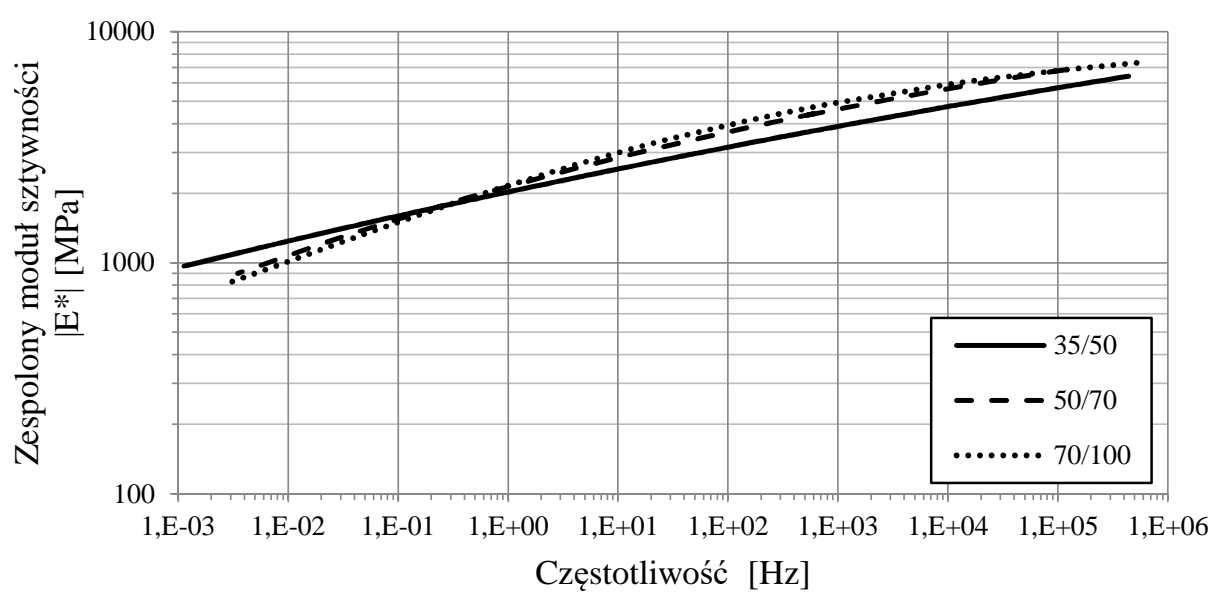

Rys. 4. Krzywe wiodące modułów zespolonych mieszanek MCAS z asfaltem spienionym o penetracjach $35 / 50,50 / 70$ i $70 / 100$ dla temperatury $20^{\circ} \mathrm{C}$

Fig. 4. Complex modulus master curves of CRM mixes with 35/50, 50/70, and 70/100 penetration foamed bitumen at $20^{\circ} \mathrm{C}$

W przypadku mieszanek recyklowanych na zimno, inni badacze (m.in. [5]) wskazują na trudności w spełnieniu założenia TTSP dla kąta przesunięcia fazowego, co uniemożliwia często dopasowanie pojedynczej krzywej wiodącej dla tego parametru. Autorzy w badanych mieszankach MCAS odnotowali zauważalnie gorsze dopasowanie wartości kąta przesunięcia fazowego $\phi$, nie na tyle jednak, aby utworzenie krzywych wiodących przy obliczonych wcześniej współczynnikach przesunięcia temperaturowego $a_{T}$ było niemożliwe. Przebieg utworzonych krzywych wiodących (rys. 5) jeszcze bardziej niż poprzednie zależności wskazuje na odmienne zachowanie mieszanki $\mathrm{MCAS}_{35 / 50}$, która w całym spektrum częstotliwości charakteryzuje się mniejszą zmiennością wartości kąta przesunięcia fazowego.

\section{Wnioski}

Porównując wyniki uzyskane dla mieszanek $\mathrm{MCAS}_{50 / 70}$ i $\mathrm{MCAS}_{70 / 100}$ stwierdzić można, iż rodzaj zastosowanego nowego lepiszcza miał niewielki wpływ na właściwości lepkosprężyste recyklowanej podbudowy. Uzyskane różnice w wartościach modułów dynamicznych i kątów przesunięcia fazowego mieszczą się w granicy ok. $11 \%$ dokładności metody oszacowanej zgodnie z AASHTO TP 62-07 (2009).

$\mathrm{W}$ przypadku mieszanki $\mathrm{MCAS}_{35 / 50}$ ocena jest utrudniona, na co wskazują nieciągłości w przestrzeni Blacka, które mogły mieć swoje źródło już na etapie wytwarzania mieszanki. Analizowane zagadnienie wymaga dalszych badań w celu potwierdzenia uzyskanych wyników, badań dotyczących trwałości zmęczeniowej mieszanek MCAS, oraz ich zachowania w zakresie dużych odkształ- 
ceń. Przedstawione wyniki badań Autorów stawiają w dobrym świetle zapisy nowego katalogu typowych konstrukcji podatnych i półsztywnych odnoszące się do projektowania konstrukcji nawierzchni z mieszankami MCAS.

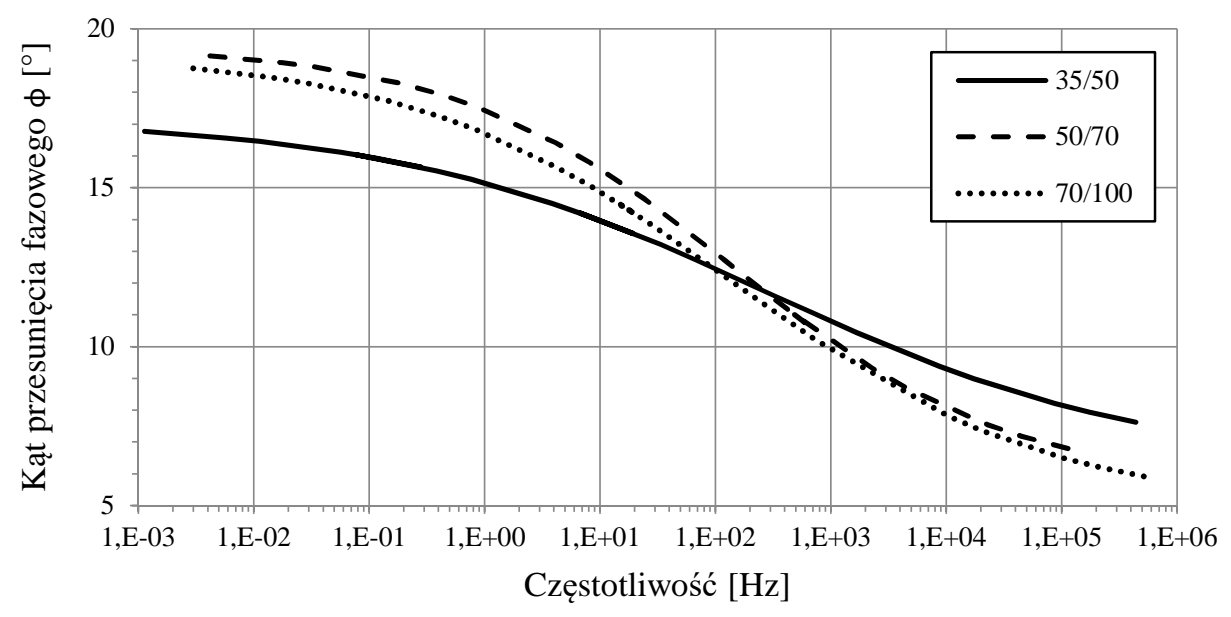

Rys. 5. Krzywe wiodące kątów przesunięcia fazowego mieszanek MCAS z asfaltem spienionym o penetracjach $35 / 50,50 / 70$ i $70 / 100$ dla temperatury $20^{\circ} \mathrm{C}$

Fig. 5. Phase angle master curves for CRM mixes with 35/50, 50/70, and $70 / 100$ penetration foamed bitumen at $20^{\circ} \mathrm{C}$

\section{Literatura}

[1] Airey G.D., Rahimzadeh B., Collop A.C., Viscoelastic linearity limits for bituminous materials, Materials and Structures/Matériaux et Constructions, Vol. 36 (2003), p. 643-647.

[2] Chomicz-Kowalska A.: Zastosowanie recyklingu na zimno z asfaltem spienionym w regionie świętokrzyskim - Część 1, Drogownictwo , nr 6 (2015), s. 172-176.

[3] Chomicz-Kowalska A.: Zastosowanie recyklingu na zimno z asfaltem spienionym W regionie świętokrzyskim - Część 2, Drogownictwo, nr 2 (2016), s. 46-54.

[4] Chomicz-Kowalska A., Maciejewski K.: Multivariate optimization of recycled road base cold mixtures withfoamed bitumen. Procedia Engineering 108 (2015), s. 436-444.

[5] Godenzoni C., Graziani A., Bocci M.: Influence of reclaimed asphalt content on the complex modulus of cement bitumen treated materials. Bituminous Mixtures \& Pavements VI, 2015, s 589-596. DOI: 10.1201/b18538-84.

[6] Godenzoni C., Graziani A., Perraton D.: Complex modulus characterisation of coldrecycled mixtures with foamed bitumen and different contents of reclaimed asphalt, Road Materials and Pavement Design (2016), DOI: 10.1080/14680629.2016.1142467.

[7] Iwański M, Chomicz-Kowalska A., Maciejewski K.: Application of synthetic wax for improvement of foamed bitumen parameters, Construction and Building Materials, Vol. 83 (2015), pp. 62-69, DOI: 10.1016/j.conbuildmat.2015.02.060. 
[8] Iwański M, Chomicz-Kowalska A., Ramiączek P., Maciejewski K., Iwański M. M.: Wpływ laboratoryjnych metod zagęszczania na właściwości fizykomechaniczne recyklowanych mieszanek mineralno-asfaltowych z asfaltem spienionym. Budownictwo i Architektura, Vol. 13, nr 1 (2014), s. 53-62.

[9] Nguyen M.L, Sauze'at C., Di Benedetto H., Tapsoba N.: Validation of the timetemperature superposition principle for crack propagation in bituminous mixtures Materials and Structures 7/2013, DOI 10.1617/s11527-012-9954-7.

[10] Olard F., Di Benedetto H.: General 2S2P1D model and relation between the linear viscoelastic behaviours of bituminous binders and mixes, Road Materials and Pavement Design, 4:2, 185-224, DOI: 10.1080/14680629.2003.9689946.

[11] Zhao Y., Kim R.Y.: The time-temperature superposition for asphalt mixtures with growing damage and permanent deformation in compression. TRB 2003 Annual Meeting.

\section{INFLUENCE OF BITUMEN TYPE ON VISCO-ELASTIC PROPERTIES OF COLD RECYCLED MIXES WITH FOAMED BITUMEN}

\section{S u m m a r y}

The article presents results concerning visco-elastic properties of deep cold recycled mixes with foamed bitumen, in scope of the penetration range of the new added bitumen (in range od 35/50 to 70/100). The recycled mixes contained 50\% of reclaimed asphalt and 30\% of reclaimed crushed stone mase and $20 \%$ of virgin aggregates. Portland cement was used as a biding agent in amount of $2 \%$ and $2.5 \%$ of foamed bitumen was added. The samples prepared in gyratory compactor were subjected to cyclic compressive loading in accordance with AASHTO TP 62-07 (2009) in different temperatures $\left(-10^{\circ} \mathrm{C}, 4^{\circ} \mathrm{C}, 21^{\circ} \mathrm{C}, 37,4^{\circ} \mathrm{C}\right)$ and at 6 frequency sweeps at each temperature $(25 \mathrm{~Hz}$, $10 \mathrm{~Hz}, 5 \mathrm{~Hz}, 1 \mathrm{~Hz}, 0,5 \mathrm{~Hz}, 0,1 \mathrm{~Hz}$ ). For all of the three mixes the values of complex moduli and phase angles were obtained. The utilization of time-temperature superposition principle enabled to shift the experimental data in the frequency domain and to fit sigmoidal functions, resulting in a fitting of master curves for complex moduli and phase angles. The construction of master curves as a function of loading frequency made it possible to compare the visco-elastic properties of the produced mixes with foamed bitumen. No significant differences were found between the mixes containing new 50/70 and 70/100 bitumen, whereas the mix with 35/50 was different.

Keywords: foamed bitumen, CRM, cold recycled mixes, base course, complex modulus

Przestano do redakcji: 07.06.2016 $r$.

Przyjęto do druku: 30.06.2016r.

DOI: $10.7862 / r b .2016 .75$ 